\title{
Discovery of an inhibitor of the production of the Pseudomonas aeruginosa virulence factor pyocyanin in wild-type cells
}

\author{
Bernardas Morkunas ${ }^{1}$, Balint Gal ${ }^{2}$, Warren R. J. D. Galloway², James T. Hodgkinson², \\ Brett M. Ibbeson ${ }^{2}$, Yaw Sing Tan ${ }^{2,3}$, Martin Welch ${ }^{1}$ and David R. Spring ${ }^{* 2}$
}

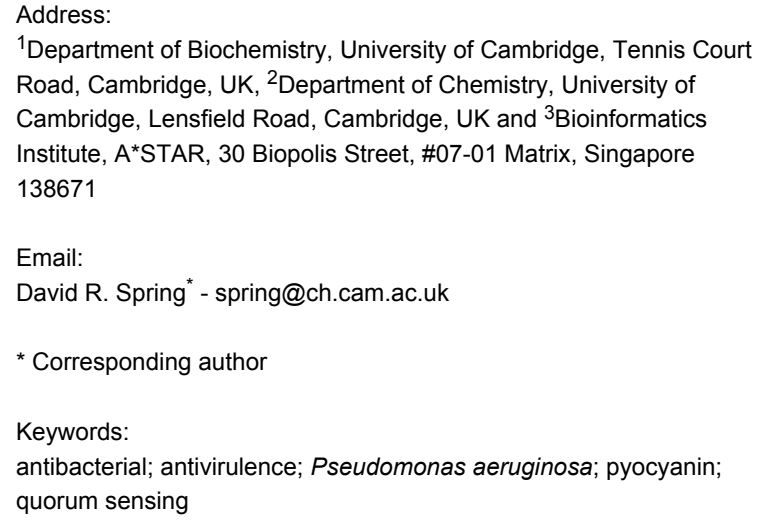

\author{
Beilstein J. Org. Chem. 2016, 12, 1428-1433. \\ doi:10.3762/bjoc.12.137 \\ Received: 18 March 2016 \\ Accepted: 30 June 2016 \\ Published: 11 July 2016 \\ Associate Editor: S. Flitsch \\ (C) 2016 Morkunas et al.; licensee Beilstein-Institut. \\ License and terms: see end of document.
}

\begin{abstract}
Pyocyanin is a small molecule produced by Pseudomonas aeruginosa that plays a crucial role in the pathogenesis of infections by this notorious opportunistic pathogen. The inhibition of pyocyanin production has been identified as an attractive antivirulence strategy for the treatment of $P$. aeruginosa infections. Herein, we report the discovery of an inhibitor of pyocyanin production in cultures of wild-type $P$. aeruginosa which is based around a 4-alkylquinolin-2(1H)-one scaffold. To the best of our knowledge, this is the first reported example of pyocyanin inhibition by a compound based around this molecular framework. The compound may therefore be representative of a new structural sub-class of pyocyanin inhibitors, which could potentially be exploited in in a therapeutic context for the development of critically needed new antipseudomonal agents. In this context, the use of wild-type cells in this study is notable, since the data obtained are of direct relevance to native situations. The compound could also be of value in better elucidating the role of pyocyanin in P. aeruginosa infections. Evidence suggests that the active compound reduces the level of pyocyanin production by inhibiting the cell-cell signalling mechanism known as quorum sensing. This could have interesting implications; quorum sensing regulates a range of additional elements associated with the pathogenicity of $P$. aeruginosa and there is a wide range of other potential applications where the inhibition of quorum sensing is desirable.
\end{abstract}

\section{Findings}

The Gram-negative bacterium Pseudomonas aeruginosa is a clinically important opportunistic human pathogen [1]. This opportunistic pathogen is well known to be a challenging infec-

tion to completely eradicate in infected patients due to high levels of intrinsic resistance to a wide variety of antibiotics [1-6] and the tendency of $P$. aeruginosa cells to form antibiotic- 
resistant biofilms [7-9]. The incidence of multidrug-resistant $P$. aeruginosa infections is on the rise on a global scale [8-10] and this bacterium is now considered to have joined the ranks of the 'superbugs' [1]. Thus, there is an urgent need to discover new therapeutic strategies to combat $P$. aeruginosa infections [1-12].

$P$. aeruginosa can secrete small organic molecules, exoenzymes, tissue degrading enzymes, toxins and other substrates which damage physiological functions of the host causing disease, often termed 'virulence factors' [13-16]. Pyocyanin is an important redox active small molecule virulence factor which is widely considered to play a crucial role in the pathogenesis of $P$. aeruginosa infections (Figure 1) $[8,9,17,18]$. The inhibition of pyocyanin production has been identified as an attractive antivirulence strategy for the treatment of $P$. aeruginosa infections $[8,9,19]$. Herein, we report the discovery of a potent inhibitor of pyocyanin production in cultures of wildtype $P$. aeruginosa which is based around a 4-alkylquinolin$2(1 H)$-one framework. To the best of our knowledge, this is the first reported example of the inhibition of this phenotype by a member of this structural sub-class. Thus, a promising new scaffold for pyocyanin inhibition has been identified.<smiles>CCNC(=O)N[C@H]1CCOC1=O</smiles><smiles>CNc1[nH]c2ccccc2c(=O)c1O</smiles><smiles>CCCC(=O)CC(=O)N[C@H]1CCOC1=O</smiles><smiles></smiles><smiles>COC(=O)CC(=O)Nc1cccc(OC)c1</smiles>

Figure 1: BHL and OdDHL are two natural AHL-based signaling molecules used by $P$. aeruginosain quorum sensing. PQS is a natural quinolone signaling molecule also used by $P$. aeruginosa in quorum sensing. Pyocyanin is a $P$. aeruginosa virulence factor. Compound 1 is an abiotic OdDHL-mimic which can inhibit pyocyanin production $[8,9]$.

A cell-cell signalling process known as quorum sensing regulates pyocyanin production by $P$. aeruginosa $[8,9,20]$. This bacterium uses (at least) three different types of quorum sensing systems. Two of the QS signaling systems in P. aeruginosa utilise $\mathrm{N}$-acylated-L-homoserine lactones (AHLs) as signalling molecules [20-22]. The rhl system utilises $N$-butanoyl-Lhomoserine lactone (BHL) and it's cognate receptor RhlR [20-
22]. The las system utilises $N$-(3-oxododecanoyl)-L-homoserine lactone (OdDHL) and it's cognate receptor LasR (Figure 1) [2022]. Interlinking these two AHL signalling systems is a third signaling system utilising a quinolone signalling molecule (termed Pseudomonas quinolone signal, PQS) [20] to form an intricate hierarchical signaling network with the Las system at the top of the network. The regulator of the pyocyanin biosynthesis genes is RhlR and transcription of the $r h l R$ gene is itself regulated by LasR. Hence, it has been hypothesised that LasR inhibition should result in the attenuation of pyocyanin production $[8,9,20]$. This hypothesis has been validated with a number of synthetic small molecules which inhibit LasR and pyocyanin production, respectively [8,9,20,23-26]. Many such inhibitors of pyocyanin biosynthesis are based on the same general structural framework as OdDHL. For example, we have recently reported the discovery of various OdDHL mimics which can inhibit pyocyanin production in cultures of wild-type $P$. aeruginosa, with compound $\mathbf{1}$ found to be the most potent (Figure 1) [9]. Inspired by these results, we sought to examine the ability of other OdDHL analogues to inhibit this phenotype. Our standard synthetic route towards these derivatives involves coupling of $\mathbf{2}$ with aromatic amines to generate the corresponding amides, followed by acetal group removal under acidic conditions (Scheme 1) [9]. However, when the product of the reaction of $\mathbf{2}$ with $\mathbf{3}$ was treated with TFA, compound $\mathbf{4}$ was generated (Scheme 1). The protected amide intermediate is known to form; presumably upon treatment with acid the liberated ketone group is then attacked intramolecularly by the electron-rich aromatic ring system to form the bicyclic ring system. Other synthetic routes to such 4-alkylquinolin-2(1H)-one analogues involve intramolecular cyclisation of an analogous $\beta$-ketoamide in sulphuric acid [27], or pallidum catalysed intramolecular cyclisation of an acetylene derivative under acidic conditions [28].

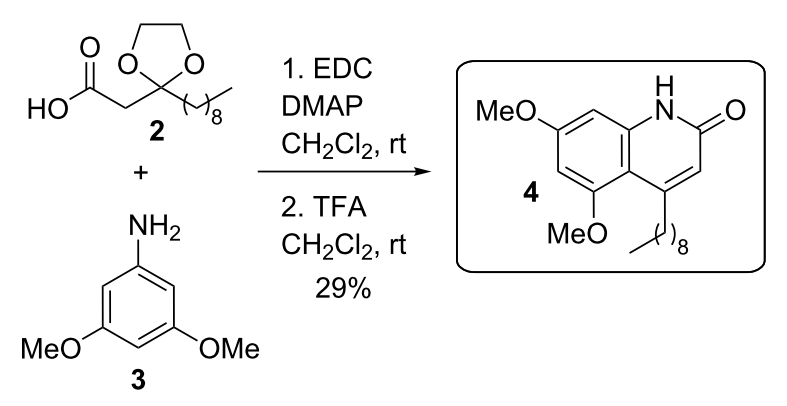

Scheme 1: Unexpected synthesis of compound 4. The synthesis of 2 was achieved by a previously reported route [9].

The 4-alkylquinolin-2(1H)-one molecular scaffold of compound 4 is clearly distinct from that of AHLs; to the best of our knowledge, compounds of this structural sub-class have never 
been screened for the ability to modulate pyocyanin production (or any other quorum sensing-regulated phenotypes). Thus, quinolone 4 was evaluated for its ability to inhibit pyocyanin production by the wild-type $P$. aeruginosa strain PAO1 (Figure 2a). We chose to work with wild-type cells as the data obtained would be of more direct relevance to native situations than if biosensor strains were used [9]. The compound was found to be very active by this assay, inhibiting the production of pyocyanin by $86 \pm 1 \%$ without affecting bacterial growth (at a concentration of $200 \mu \mathrm{M}$, tested as a suspension in DMSO). Pleasingly this level of activity is comparable to the OdDHLmimic 1 ( $93 \pm 2 \%$ inhibition of pyocyanin production determined under identical assay conditions to those described in Figure 2) [9]. Though there are many examples of AHL-based compounds with the ability to reduce pyocyanin production, there are several well-documented problems associated with the potential use of molecules based on the AHL framework in a therapeutic context $[9,12,20]$. Thus, there is interest in the identification of new structural classes of small-molecule inhibitors of pyocyanin production, such as that represented by compound 4 [12]. The effect of varying the concentration of 4 upon pyocyanin production was next examined (Figure $2 \mathrm{~b}$ ). Compound 4 was found to inhibit this phenotype in a concentrationdependent manner above $20 \mu \mathrm{M}$, with an $\mathrm{IC}_{50} \sim 70 \mu \mathrm{M}$. Interestingly, this data suggests that $\mathbf{4}$ may have slight agonist activity at low concentrations. This type of behaviour has previously been observed for AHL-based modulators of quorum sensing. Many such compounds have been identified that can both slightly activate and inhibit a quorum sensing circuit depending on their concentration [20]. This result could also potentially be attributed to the use of wild-type cells. Endogenous AHL levels in such systems could conceivably fluctuate in an unpredictable fashion, which would be expected to affect the level of pyocyanin production.

Compounds that attenuate pyocyanin biosynthesis in $P$. aeruginosa may be inhibitors of LasR-based quorum sensing. However, it has previously been reported that $P$. aeruginosa can exhibit near full virulence, including pyocyanin production, in the absence of LasR utilising solely the rhl, and pqs signalling systems [30]. Additional studies have demonstrated that the straight forward hierarchical QS network (with the las system at the forefront followed by the lower ranked rhl and pqs signalling system) is more elaborate and complex than this hierarchical structure $[8,9,30]$. Taking these studies into account it is possible that pyocyanin inhibitors in P.aeruginosa are not directly inhibiting LasR but have an alternate mode of action(s), this hypothesis should not be completely ruled out. This may be especially relevant for compounds such as $\mathbf{4}$, which are clearly structurally distinct from OdDHL, the natural LasR agonist [12].

In order to further explore the possibility that compound $\mathbf{4}$ may act as a LasR antagonist, it was subjected to molecular docking studies against the $P$. aeruginosa LasR ligand-binding domain (LBD) [31]. Specifically, both OdDHL and 4 were docked into the OdDHL binding pocket of two LasR LBD structures, one with a bridging water molecule, which is known to be involved in a hydrogen bonding between OdDHL and Arg61 (Figure 3a) [32], and one without. In addition, both rigid and flexible con-
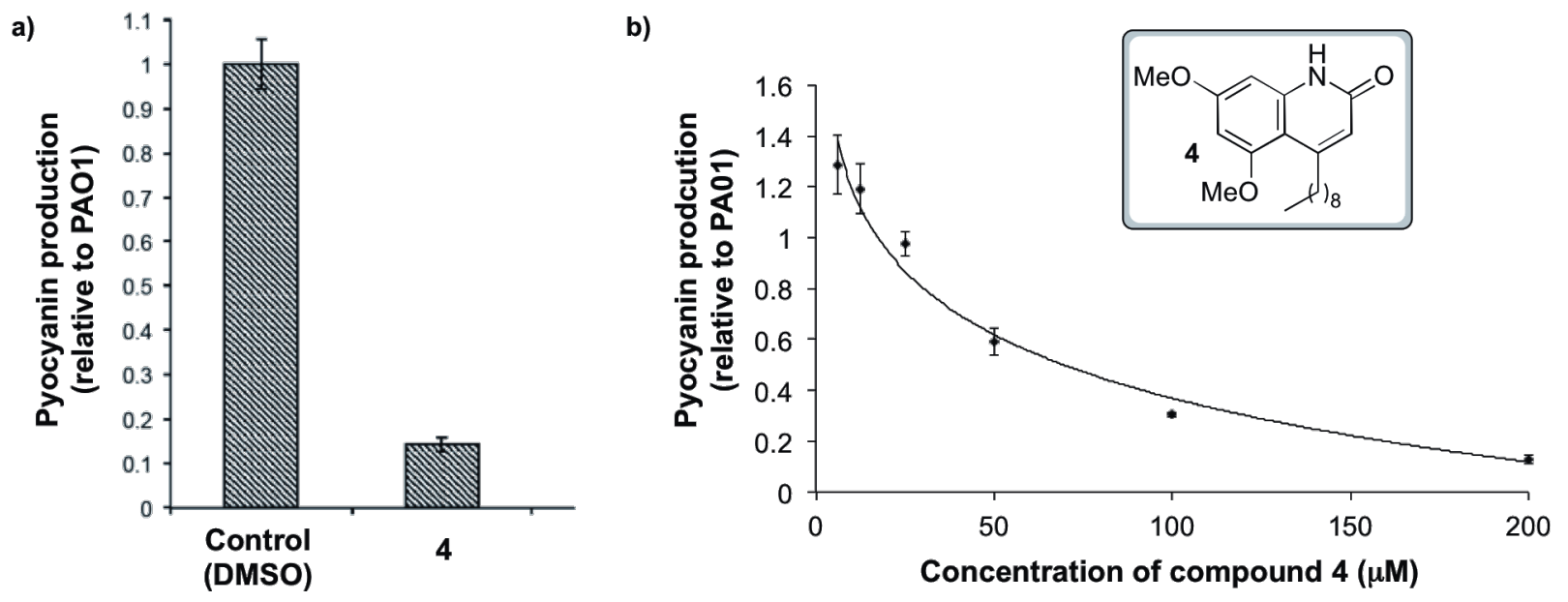

Figure 2: a) Inhibitory effect of compound 4 (200 $\mu \mathrm{M}$ suspension in DMSO) on pyocyanin production in PAO1. DMSO was added as a control. No effect on growth was observed for the compound. b) Effect of various concentrations of 4 on pyocyanin production in PAO1. A logarithmic trend line has been fitted to the averaged data points (calculated using Microsoft ${ }^{\circledR}$ Excel ${ }^{\circledR}$ 2011). Growth conditions in both cases: cultures of PAO1 were grown in Luria broth medium in the presence of compound 4 (at the indicated concentration) with good aeration at $37^{\circ} \mathrm{C}$ for 13 hours (initial $\mathrm{OD}_{600}$ of 0.05 $t=0)$. After growth, pyocyanin production was quantified as previously described [29]. The data represents the averages and standard deviations from the results of three independent biological repeats. 
formations of LasR LBD were used in the docking runs. Tyr47 and Arg61 exhibit considerable variation in their side-chain conformations in various crystal structures of LasR LBD complexes and hence, they were made flexible in the flexible receptor docking runs. The best score for OdDHL $(-9.1 \mathrm{kcal} / \mathrm{mol})$ was obtained from the rigid receptor docking run with water. The docked and crystallographic conformations of OdDHL agree closely with each other (root mean square deviation $[\mathrm{RMSD}]=0.54 \AA$ ) in the presence of the crystallographic water molecule. The RMSD between the docked and crystallographic conformations of OdDHL increases to $1.1 \AA$ in the absence of water. This demonstrates the importance of the bridging water molecule in the accurate reproduction of the crystallographic binding mode of OdDHL. Conversely, the best score for 4 $(-9.7 \mathrm{kcal} / \mathrm{mol})$ was obtained when it was docked into the flexible conformation of LasR LBD without water. In order to accommodate the bicyclic moiety of 4, Arg61, which points into the OdDHL binding pocket in the crystal structure of LasR LBD bound to OdDHL (Figure 3a) [31], is displaced out towards the bulk solvent (Figure $3 b$ ). This alternative conformation of Arg61 has also been observed in several structures of LasR LBD in complex with triphenyl ligands [33]. In this docked pose, interactions between $\mathbf{4}$ and Las LBD are predominantly hydrophobic in nature as only one hydrogen bond is formed between the oxygen of a methoxy group of $\mathbf{4}$ to Ser129. This is in contrast to OdDHL, which forms five hydrogen bonds as well as extensive hydrophobic interactions with LasR LBD. Given its highly favourable docking score, it is plausible that compound 4 may bind LasR at the OdDHL binding site, and thus be capable of competitively disrupting OdDHL-dependent activation of LasR and thereby inhibiting pyocyanin production.

\section{Conclusion}

In conclusion, we have reported the discovery of $\mathbf{4}$, a potent inhibitor of pyocyanin in wild-type $P$. aeruginosa. To the best of our knowledge this is the first reported example of pyocyanin inhibition by a compound based around a 4-alkylquinolin2(1H)-one scaffold. Compound 4 is therefore representative of a new structural sub-class of pyocyanin inhibitors, which could potentially be exploited in a therapeutic context for the development of novel antipseudomonal agents. In this context, the use of wild-type cells in this study is notable, since the data obtained are of more direct relevance to native situations than if biosensor strains (tailored bacterial reporter strains) were used (which is typically the case) [9]. Conceivably $\mathbf{4}$ could also be of value in better elucidating the role of pyocyanin in $P$. aeruginosa infections. Of wider significance, the identification of small molecules with antivirulence activity is needed in order to more fully evaluate the therapeutic potential of targeting virulence factors $[8,9,34]$. There is some evidence suggesting that 4 reduces the level of pyocyanin production by disrupting

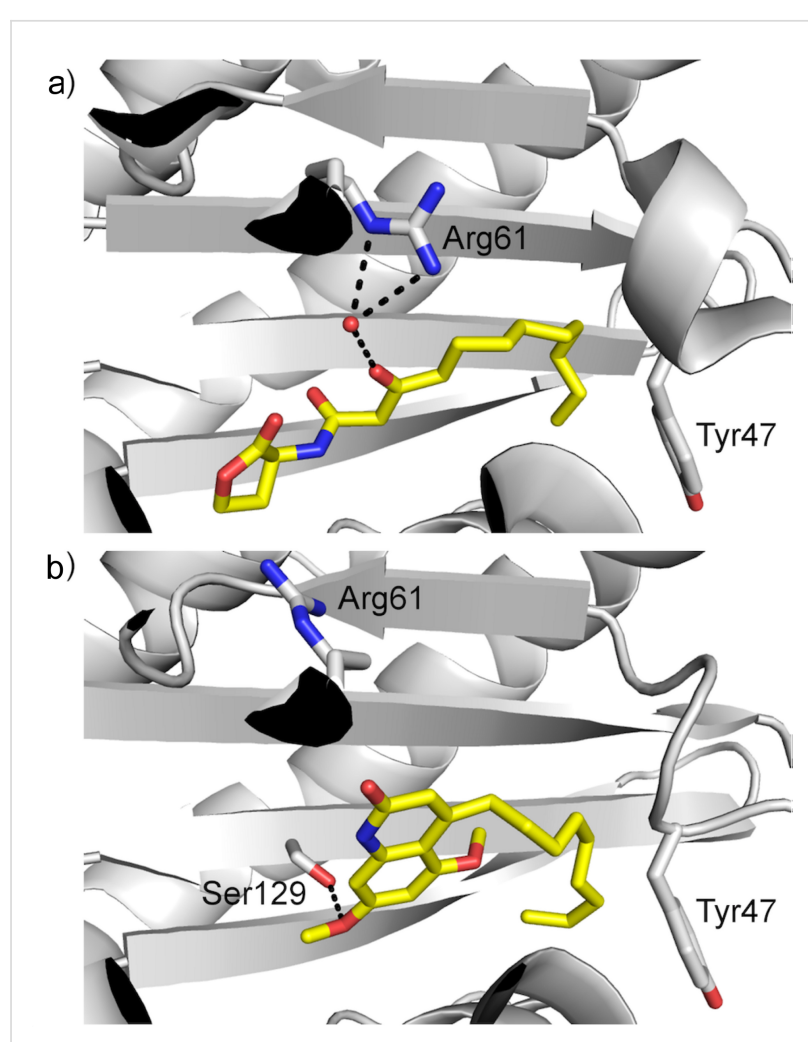

Figure 3: Binding poses of OdDHL and compound 4 in OdDHL binding site. Hydrogen bonds are shown in black dotted lines. a) Crystal structure of OdDHL bound to LasR LBD (PDB 2UV0 [31]). b) Top-scoring pose of compound $\mathbf{4}$ obtained by docking into LasR LBD.

OdDHL-dependent activation of LasR; that it, compound 4, may be a LasR antagonist and an inhibitor of LasR-based quorum sensing. This could have interesting implications; quorum sensing regulates a range of additional elements associated with the pathogenicity of $P$. aeruginos $a$ and there is a wide range of other potential applications where the inhibition of quorum sensing is desirable $[8,9,20]$. In this context, it is worth noting that compound $\mathbf{4}$ is structurally reminiscent of 2-alkyl$4(1 H)$-quinolones, which are known to have effects upon quorum sensing in $P$. aeruginosa, including pyocyanin production $[8,9,35]$. Thus, the cognate receptor of PQS, PqsR, could be a target of $\mathbf{4}$; however, other targets of $\mathbf{4}$ cannot as yet be ruled out. Further investigations into the mode of action of $\mathbf{4}$ and structure-activity relationship studies are ongoing and results will be reported in due course.

\section{Supporting Information}

\section{Supporting Information File 1}

Experimental details and analytical data.

[http://www.beilstein-journals.org/bjoc/content/ supplementary/1860-5397-12-137-S1.pdf] 


\section{Acknowledgements}

The research leading to these results has received funding from the European Research Council under the European Union's Seventh Framework Programme (FP7/2007-2013)/ERC grant agreement no [279337/DOS]. In addition, the group research was supported by grants from the Engineering and Physical Sciences Research Council, Biotechnology and Biological Sciences Research Council, Medical Research Council and Welcome Trust. Y.S.T. was supported by an A*STAR Graduate Scholarship.

\section{References}

1. Breidenstein, E. B. M.; de la Fuente-Núñez, C.; Hancock, R. E. W. Trends Microbiol. 2011, 19, 419-426. doi:10.1016/j.tim.2011.04.005

2. Mesaros, N.; Nordmann, P.; Plésiat, P.; Roussel-Delvallez, M.; Van Eldere, J.; Glupczynski, Y.; Van Laethem, Y.; Jacobs, F.; Lebecque, P.; Malfroot, A.; Tulkens, P. M.; Van Bambeke, F. Clin. Microbiol. Infect. 2007, 13, 560-578. doi:10.1111/j.1469-0691.2007.01681.x

3. Popat, R.; Crusz, S. A.; Diggle, S. P. Br. Med. Bull. 2008, 87, 63-75. doi:10.1093/bmb/ldn030

4. Grossi, P.; Dalla Gasperina, D. Expert Rev. Anti-Infect. Ther. 2006, 4, 639-662. doi:10.1586/14787210.4.4.639

5. Lanini, S.; D'Arezzo, S.; Puro, V.; Martini, L.; Imperi, F.; Piselli, P.; Montanaro, M.; Paoletti, S.; Visca, P.; Ippolito, G. PLoS One 2011, 6, e17064. doi:10.1371/journal.pone.0017064

6. Diggle, S. P.; Winzer, K.; Chhabra, S. R.; Chhabra, S. R.; Worrall, K. E.; Cámara, M.; Williams, P. Mol. Microbiol. 2003, 50, 29-43. doi:10.1046/j.1365-2958.2003.03672.x

7. Antunes, L. C. M.; Ferreira, R. B. R.; Buckner, M. M. C.; Finlay, B. B. Microbiology (London, U. K.) 2010, 156, 2271-2282. doi:10.1099/mic.0.038794-0

8. Baker, Y. R.; Galloway, W. R. J. D.; Hodgkinson, J. T.; Spring, D. R. Molecules 2013, 18, 11783-11796. doi:10.3390/molecules181011783

9. Morkunas, B.; Galloway, W. R. J. D.; Wright, M.; Ibbeson, B. M.; Hodgkinson, J. T.; O'Connell, K. M. G.; Bartolucci, N.; Della Valle, M.; Welch, M.; Spring, D. R. Org. Biomol. Chem. 2012, 10, 8452-8464. doi:10.1039/c2ob26501j

10. Zaborina, O.; Kohler, J. E.; Wang, Y.; Bethel, C.; Shevchenko, O.; Wu, L.; Turner, J. R.; Alverdy, J. C. Ann. Clin. Microbiol. Antimicrob. 2006, 5, No. 14. doi:10.1186/1476-0711-5-14

11. Kipnis, E.; Sawa, T.; Wiener-Kronish, J. Med. Mal. Infect. 2006, 36, 78-91. doi:10.1016/j.medmal.2005.10.007

12. Miller, L. C.; O'Loughlin, C. T.; Zhang, Z.; Siryaporn, A.; Silpe, J. E.; Bassler, B. L.; Semmelhack, M. F. J. Med. Chem. 2015, 58, 1298-1306. doi:10.1021/jm5015082

13. Strateva, T.; Mitov, I. Ann. Microbiol. (Heidelberg, Ger.) 2011, 61, 717-732. doi:10.1007/s13213-011-0273-y

14. Clatworthy, A. E.; Pierson, E.; Hung, D. T. Nat. Chem. Biol. 2007, 3, 541-548. doi:10.1038/nchembio.2007.24

15. Barczak, A. K.; Hung, D. T. Curr. Opin. Microbiol. 2009, 12, 490-496. doi:10.1016/j.mib.2009.06.012

16. O'Malley, Y. Q.; Reszka, K. J.; Spitz, D. R.; Denning, G. M.; Britigan, B. E. Am. J. Physiol.: Lung Cell. Mol. Physiol. 2004, 287, L94-L103. doi:10.1152/ajplung.00025.2004

17. Lau, G. W.; Hassett, D. J.; Ran, H.; Kong, F. Trends Mol. Med. 2004, 10, 599-606. doi:10.1016/j.molmed.2004.10.002
18. Lau, G. W.; Ran, H.; Kong, F.; Hassett, D. J.; Mavrodi, D. Infect. Immun. 2004, 72, 4275-4278. doi:10.1128/IAl.72.7.4275-4278.2004

19. Allen, R. C.; Popat, R.; Diggle, S. P.; Brown, S. P. Nat. Rev. Microbiol. 2014, 12, 300-308. doi:10.1038/nrmicro3232

20. Galloway, W. R. J. D.; Hodgkinson, J. T.; Bowden, S. D.; Welch, M.; Spring, D. R. Chem. Rev. 2011, 111, 28-67. doi:10.1021/cr100109t

21. Galloway, W. R. J. D.; Hodgkinson, J. T.; Bowden, S.; Welch, M.; Spring, D. R. Trends Microbiol. 2012, 20, 449-458. doi:10.1016/j.tim.2012.06.003

22. Welch, M.; Mikkelsen, H.; Swatton, J. E.; Smith, D.; Thomas, G. L.; Glansdorp, F. G.; Spring, D. R. Mol. BioSyst. 2005, 1, 196-202. doi:10.1039/B505796P

23. Whitehead, N. A.; Barnard, A. M. L.; Slater, H.; Simpson, N. J. L.; Salmond, G. P. C. FEMS Microbiol. Rev. 2001, 25, 365-404. doi:10.1111/j.1574-6976.2001.tb00583.x

24. Taha, M. O.; Al-Bakri, A. G.; Zalloum, W. A. Bioorg. Med. Chem. Lett. 2006, 16, 5902-5906. doi:10.1016/j.bmcl.2006.08.069

25. Smith, K. M.; Bu, Y.; Suga, H. Cell Chem. Biol. 2003, 10, 563-571. doi:10.1016/S1074-5521(03)00107-8

26. Ishida, T.; Ikeda, T.; Takiguchi, N.; Kuroda, A.; Ohtake, H.; Kato, J. Appl. Environ. Microbiol. 2007, 73, 3183-3188. doi:10.1128/AEM.02233-06

27. Sharma, G. V. M.; Ilangovan, A.; Narayanan, V. L.; Gujar, M. K. Tetrahedron 2003, 59, 95-99. doi:10.1016/S0040-4020(02)01456-4

28. Jia, C.; Piao, D.; Kitamura, T.; Fujiwara, Y. J. Org. Chem. 2000, 65, 7516-7522. doi:10.1021/jo000861q

29. Essar, D. W.; Eberly, L.; Hadero, A.; Crawford, P. J. Bacteriol. 1990, 172, 884-900.

30. Dekimpe, V.; Déziel, E. Microbiology (London, U. K.) 2009, 155, 712-723. doi:10.1099/mic.0.022764-0

31. Bottomley, M. J.; Muraglia, E.; Bazzo, R.; Carfi, A. J. Biol. Chem. 2007, 282, 13592-13600. doi:10.1074/jbc.M700556200 See for crystal structure PDB code 2 UV0.

32. Dolinsky, T. J.; Czodrowski, P.; Li, H.; Nielsen, J. E.; Jensen, J. H.; Klebe, G.; Baker, N. A. Nucleic Acids Res. 2007, 35 (Suppl. 2), W522-W525. doi:10.1093/nar/gkm276

33. Zou, Y.; Nair, S. K. Chem. Biol. 2009, 16, 961-970. doi:10.1016/j.chembiol.2009.09.001

34. Garner, A. L.; Struss, A. K.; Fullagar, J. L.; Agrawal, A.; Moreno, A. Y.; Cohen, S. M.; Janda, K. D. ACS Med. Chem. Lett. 2012, 3, 668-672. doi:10.1021/ml300128f

35. Heeb, S.; Fletcher, M. P.; Chhabra, S. R.; Diggle, S. P.; Williams, P.; Cámara, M. FEMS Microbiol. Rev. 2011, 35, 247-274. doi:10.1111/j.1574-6976.2010.00247.x 


\section{License and Terms}

This is an Open Access article under the terms of the Creative Commons Attribution License

(http://creativecommons.org/licenses/by/2.0), which permits unrestricted use, distribution, and reproduction in any medium, provided the original work is properly cited.

The license is subject to the Beilstein Journal of Organic Chemistry terms and conditions:

(http://www.beilstein-journals.org/bjoc)

The definitive version of this article is the electronic one which can be found at:

doi:10.3762/bjoc. 12.137 